\title{
DESINSTITUCIONALIZAÇÃO: análise dos direitos fundamentais e saúde mental pública
}

\section{Victoria Muniz Cabral da Silva Paolla Vieira Lima}

\section{RESUMO}

0 artigo a seguir aborda a política pública de desinstitucionalização da saúde mental. Para tanto, utilizaremos os indicadores do município do Rio de Janeiro, produzidos pela Secretaria Municipal de Saúde. Com isso, poderemos verificar a congruência da implementação da supradita política pública, estabelecendo uma análise com seus objetivos. Além disso, o estudo dessa correlação trará subsídios para averiguar se a desinstitucionalização como política pública está apropriada com a concretização dos direitos fundamentais. A metodologia será norteada pela observação de indicadores produzidos pelo monitoramento interno, baseado na abordagem teórica multidisciplinar entre direitos e psiquiatria.

PALAVRAS-CHAVE: Saúde mental; Desinstitucionalização; Política pública; Direitos fundamentais; lindicadores.

\section{ABSTRACT}

The following paper concerns the public policy of deinstitutionalization of mental health. To do so, we will use the indicators of the municipality of Rio de Janeiro, produced by the Municipal Health Department. According to this, we will be able to verify the congruence of the implementation of the public policy, establishing an analysis with its objectives. In addition, the study of this correlation will provide insights into whether deinstitutionalization as a public policy is appropriate with the realization of fundamental rights. The methodology will be guided by the observation of indicators produced by internal monitoring, based on the theoretical multidisciplinary approach between rights and psychiatry.

KEY-WORDS: Health mental; Deinstitutionalisation; Public policy; Fundamental rights; Indicators.

\section{Considerações Iniciais}

De maneira quase que contrária às artes, área em que é tratada como personificação ou romantismo, a loucura não é tratada como um ideal romantizado pela sociedade. O padrão predominante durante longo período de tempo foi o da exclusão e isolamento. Como, por exemplo, a lepra, a loucura também deveria ser algo "invisível aos olhos da sociedade", daí a existência do sistema manicomial.

O constrangimento dos loucos aos manicômios, além de impulsionar a invisibilidade social, era avaliada como a maneira mais eficaz de tratamento. Este primava pela internação dos pacientes com algum tipo de transtorno mental e só passou por uma progressiva alteração a partir dos anos 70 no Brasil, quando o isolamento e o tratamento separado da sociedade começaram a ser examinados ${ }^{2}$.

1 Este artigo foi publicado originalmente pela Revista Raízes Jurídicas, v.9, $\mathrm{n}^{\circ}$ 2, ano 2017 e pode ser acessado em: http://ojs.up.com.br/index.php/raizesjuridicas/article/view/769

2 Cf. MESQUITA, José Ferreira; NOVELLINO, Maria Sallet Ferreira; CAVALCANTI, Maria Tavares. A reforma psiquiátrica no Brasil: um novo olhar sobre o paradigma da saúde mental. In: XVII Encontro Nacional de Estudos Populacionais, ABEP. Caxambu, 2010. SOUZA, Vinícius Rauber e. Contrarreforma psiquiátrica: o modelo hospitalocêntrico nas políticas públicas em saúde mental no Rio Grande do Sul. Dissertação (Mestrado 
Tem-se, então, o começo da Reforma Psiquiátrica, cuja particularidade é o processo de desinstitucionalização da saúde mental. $O$ estopim passou por dois aspectos centrais. $O$ primeiro deles foi revelado pelos próprios trabalhadores do sistema mental (Movimento dos Trabalhadores em Saúde Mental - MTSM), que noticiaram as condições humilhantes pelas quais os pacientes eram submetidos, bem como violações de direitos humanos ${ }^{3}$. O segundo aspecto, diz respeito à evolução dos próprios conceitos da psiquiatria, ou seja, uma modificação de padrão de qual seria a melhor configuração de tratamento ${ }^{4}$.

Com isso, teve-se, também, o fechamento expressivo (ao menos redução de leitos) dos hospitais manicomiais. Entretanto, a política pública de desinstitucionalização conta com outros mecanismos "[...] que pressupõe $(m)$ transformações culturais e subjetivas na sociedade [...]" .

Assim, as psiquiatras começaram a abordar a desinstitucionalização e seus mecanismos integrantes. O fator fundamental pelo qual essa política pública será analisada envolve à tentativa de reinserir o portador de transtorno mental na coletividade. Conquanto a política pública focalize questões médicas, bem como o melhor meio de se tratar a patologia, ela inteiramente promove a relação do paciente e, portanto, revoga o status de "invisibilidade social".

Além disso, os direitos fundamentais incidem como componente importante, já que os portadores de patologia mental igualmente são sujeitos de direitos. Dessa forma, a política pública de desinstitucionalização deve ser medida a partir da existência dos direitos fundamentais.

Ademais, a dificuldade que surge é de qual seria a modo realizar a determinação do efeito positivo ou negativo. Nesse sentido, o controle do desenvolvimento da política pública advém por um diagnóstico dos dados providos pelos "indicadores", e do seu correspondente "monitoramento". A preocupação com relação às políticas públicas passa a ter três pontos-chave: i) inputs, ii) outputs e iii) outcomes ${ }^{6}$.

Resumidamente, os inputs consideram os recursos que são alocados na implementação da política pública, isto é, à parte orçamentária. Os outputs consistem em como serão implementadas as medidas das políticas públicas. E os outcomes constituem os resultados e objetivos.

A convergência desses princípios ao controle da política pública de desinstitucionalização da saúde mental será o ponto central. A motivação da preferência da saúde mental para estudo, ao invés de diversas outras políticas expressivas no Brasil, é a tentativa de romper com o afastamento dos portadores de transtorno mental na sociedade.

Com apoio desse material, o presente trabalho será organizado da seguinte maneira: o capítulo 2 aprofundará a análise do marco regulatório, dos mecanismos (outputs) e dos objetivos (outcomes) pronunciados por meio da política de desinstitucionalização.

em Ciências Sociais) - Faculdade de Filosofia e Ciências Humanas, Programa de Pós-Graduação em Ciências Sociais, Pontifícia Universidade Católica do Rio Grande do Sul (PUC/RS), Porto Alegre, 2010.

3 RIO DE JANEIRO. As residências terapêuticas no município do Rio de Janeiro: habitando a casa, a cidade e a vida. Rio de Janeiro: Secretaria Municipal de Saúde, 2014.p. 10. VIOLA, Ana Clara. Longo Caminho a percorrer na volta para a sociedade. O Ministério Público e a desinstitucionalização em saúde mental. Dissertação (Mestrado Profissional em Saúde Pública) - Escola Nacional de Saúde Pública Sérgio Arouca, Fiocruz, Rio de Janeiro, 2015. p. 22

4 VENTURINI, Ernesto. A desinstitucionalização; limites e possibilidades. Revista Brasileira de Crescimento e Desenvolvimento Humano. v. 20, n. 1, São Paulo, abr 2010. Disponível em: <http://pepsic.bvsalud. org/scielo.php? script=sci_arttext\&pid=S0104-12822010000100018\&lng=pt\&nrm=iso>. Acesso em 20 abr 2017.

5 BRASIL. Ministério da Saúde. Reforma Psiquiátrica e política de saúde mental. Conferência Regional de Reforma dos Serviços de Saúde Mental: 15 anos depois de Caracas. Nov 2015. Disponível em: <http://bvsms. saude.gov.br/bvs/publicacoes /Relatorio15_anos_Caracas.pdf>. Acesso em 16 fev 2017.p. 10-11.

6 NORTON, Andy; ELSON, Diane. What's behind the budget?Politics, rights and accountability in the budget process. London: Overseas Development Institute, 2002. Disponível em: <http://www.unicef.org/ socialpolicy/files/What_is_behind_the_budget_NortonElson02.pdf >. Acesso em 19 abr 2017. p.30-31. 
O capítulo 3 abordará os indicadores da cidade do Rio de Janeiro, com destaque a diminuição do número de leitos, que é um outcomes analisado pela política de desinstitucionalização.

A análise das informações (indicadores) adquiridos a partir dos aparelhos de monitoramento demonstrará em que medida os direitos fundamentais relatados como objetivos da política de desinstitucionalização estão sendo por ela realizados.

\section{Objetivos da política pública de desinstitucionalização da saúde mental: marcos regulatórios}

No Brasil, as discussões começaram com a Conferência Nacional de Saúde Mental (CNSM), cujo primeiro encontro aconteceu em $1987^{7}$, onde havia debates sobre a desinstitucionalização. Além disso, a Declaração de Caracas $^{8}$, adotada pela Organização Mundial de Saúde, em 1990, colaborou para a disseminação do tema relacionado à saúde mental.

Sabe-se que há previsão do direito à saúde ${ }^{9}$ desde a Constituição de 1988 , assim como os debates em torno de uma Reforma Psiquiátrica que lembre os anos 70 e 80 . Contudo, esse objeto só ganha visibilidade normativa em âmbito federal em 2001, com a Lei n. 10.216/01 ${ }^{10}$.

Durante o período em que a Lei n. 10.216/2001 esteve em tramitação no Congresso, alguns entes federados dispuseram sobre a saúde mental.

desde 1992, existem nove leis estaduais em vigor, inspiradas no Projeto de Lei Federal de autoria do deputado Paulo Delgado. Em todas, está prevista a substituição progressiva da assistência no hospital psiquiátrico por outros dispositivos ou serviços. Há incentivo para os centros de atenção diária, a utilização de leitos em hospitais gerais, a notificação da internação involuntária e a definição dos direitos das pessoas com transtornos mentais.

Apesar disso, a desinstitucionalização da saúde mental teve dificuldade de efetivação já que não havia uma comunicação adequada entre União, Estado (e Distrito Federal) e Municípios. Por isso a importância da Lei n. 10.216/01 para a solidificação desse tratamento ${ }^{11}$.

A Lei n. 10.216/01 tem somente doze artigos, por isso, fica condicionada às próximas disposições infralegais para ratificar-se. Entretanto, no ponto de vista normativo, se

7 ROSA, Abílio da Costa; LUZIO, Cristina Amélia; YASUI, Sílvio. As Conferências Nacionais de Saúde Mental e as premissas do modo psicossocial. Saúde em Debate, v. 25, n. 58, mai/ago 2001. pp. 12-25.VIOLA. Idem.

8 ORGANIZAÇÃo Mundial da Saúde (OMS). Declaração de Caracas. 14 nov 1990. Disponível em <http:// pfdc.pgr.mpf.mp.br/atuacao-e-conteudos-de-apoio/legislacao/saude-mental/declaracao_caracas $>$. Acesso em 20 de abr 2017.

9 Art. $6^{\circ}$, Art. 194 e Art. 196. BRASIL. Constituição da República Federativa do Brasil. 1988. Disponível em <http://www.planalto.gov.br/ccivil_03/constituicao/ConstituicaoCompilado.htm>. Acesso em 20 abr 2017.

10 O processo legislativo foi desatado pelo Projeto de Lei n. 3.657/89, de autoria do Deputado Federal Paulo Delgado. BRASIL. Diário do Congresso Nacional, de 29 de setembro de 1989, seção I, pp. 10.696-10.697. RIO DE JANEIRO, Secretaria Municipal da Saúde, idem. p. 7.

11 A Lei Estadual n. 6.758/95 do Rio Grande do Norte "apenas" proibia a construção e ampliação de novos hospitais psiquiátricos. Por sua vez, a Lei Estadual n. 9.716/92 do Rio Grande do Sul, em seu art. $2^{\circ}$, previa não só a desinstitucionalização, mas também narrava quais seriam os mecanismos indispensáveis para tanto.Cf. ASSEMBLEIA LEGISLATIVA DO ESTADO DO RIO GRANDE DO NORTE. Lei n. 6.758 de 04 de janeiro de 1995. Disponível em <http://www.al.rn.gov.br/portal/_ups/legislacao//6.758.pdf>. Acesso em 20 abr 2016. ASSEMBLEIA LEGISLATIVA DO ESTADO DO RIO GRANDE DO SUL. Lei n. 9716 de 07 de agosto de 1992. Disponível em <http://www.al.rs.gov.br/legis/M010/M0100099.ASP?Hid_Tipo=TEXTO\&Hid_ TodasNormas=15281\&hTexto=\&Hid_IDNorma=15281>. Acesso em 20 abr 2017. 
consolida a virada do tratamento da saúde mental mencionado na introdução. Essa Lei traz perspectivas para o dito invisível louco e passa a tratá-lo como sujeito de direitos.

Por vezes, a internação manicomial significava o fim dos vínculos sociais e afetivos dos pacientes. Em contrapartida à invisibilidade, pode-se assumir que esse era um dos principais objetivos da Lei n. 10.216/01, ainda que esses objetivos não estivessem evidenciados no texto. Então, os outcomes da política de desinstitucionalização vão além do diploma legal.

No mais, vale ressaltar que determinados outcomes são expressamente previstos no texto e teriam os objetivos da desinstitucionalização mais abrangente. No art. $2^{\circ}$, parágrafo único, inciso II, em que há a expressa previsão desse tipo de tratamento com humanidade, com responsabilidade e com a reinserção em sociedade ${ }^{12}$. Além disso, a ideia de internação hospitalar está prevista no art. $4^{\circ}$ da Lei ${ }^{13}$.

De maneira didática, têm-se os outcomes como: a ruptura com a indivisibilidade social, o fechamento de leitos e redução do modelo hospitalocêntrico e a efetividade dos direitos fundamentais. Já os outputs são os programas como: Volta Pra Casa, Serviços Residenciais Terapêuticos, Centros de Atenção Psicossocial, Rede de Atenção Psicossocial e o Programa de Desinstitucionalização.

A princípio, é plausível aceitar que o primeiro outcome, independente da indivisibilidade social é de complexa avaliação porque é consequência de uma alteração na cultura da sociedade. No entanto, por meio da ponderação do segundo outcome, qual seja o fechamento de leitos e o abandono do modelo hospitalocêntrico, é admissível concluir que medida o primeiro outcome está sendo efetivado.

A soma desses dois outcomes representaria um terceiro outcome, que seria a própria razão de ser da política pública, qual seja o modo como a desinstitucionalização torna denso o estudo do transtorno mental. As estratégias (outputs) de desinstitucionalização são:

\subsection{Centros de Atenção Psicossocial (CAPS)}

Os Centros de Atenção Psicossocial (CAPS) são os instrumentos de tratamento de quem é acometido por transtorno mental. Em linhas gerais, o que será feito com os pacientes a partir daí é decorrente da análise dos CAPS. Por isso, esse output expõe um item significativo na transferência do modelo hospitalocêntrico, já que as estratégias de desinstitucionalização do paciente são esquematizadas por eles.

As cinco modalidades de organização de CAPS possuem características parecidas. Porém, as maiores diferenças passam pelo horário de funcionamento, equipe técnica e algumas outras finalidades.

\subsection{Programa De Volta Pra Casa}

Na sequência da Lei n. 10.216/01, a Lei n. 10.708/03 tratou de criar o programa "De Volta Pra Casa", que o incentiva o acolhimento fora do hospital daqueles que se encontrem com transtorno mental. O principal mecanismo (output) consiste no auxílio-reabilitação psicossocial, que é um benefício pecuniário direcionado ao beneficiário (ou ao seu representante, em casos de incapacidade) ${ }^{14}$. Logo, esse

\footnotetext{
12 Art. $2^{\circ}$, Parágrafo único e inciso II. BRASIL. Lei n. 10.216, de 6 de abril de 2001. Disponível em <http:// www.planalto.gov.br/ccivil_03/Leis/LEIS_2001/L10216.htm>. Acesso em 20 abr 2017.

13 Art. $4^{\circ}$. BRASIL. Idem.

14 BRASIL. Lei n. 10.708, de 31 de julho de 2003. Disponível em <http://www.planalto.gov.br/ccivil_03/ Leis/2003/ L10.708.htm>. Acesso em 20 abr 2017.
} 
mecanismo tem como outcome imediato o seu requisito de concessão, que é a reinserção de loucos na sociedade.

\subsection{Rede de Atenção Psicossocial (RAPS)}

Os CAPS, juntamente com os outros mecanismos integrantes da política pública de desinstitucionalização da saúde mental, passaram a atuar de maneira integrada e articulada com o combate à dependência química, todos sob a égide do Sistema Único de Saúde. Essa integração passou a acontecer em 2011, por meio da criação da Rede de Atenção Psicossocial (RAPS), instituída pela Portaria n. 3.088, de 23 de dezembro de 2011, do Ministério da Saúde. E, mais uma vez, a busca pela reinserção está entre os objetivos expressamente prescritos nesse dispositivo, em seu art. $4^{015}$.

Com isso, a luta por um modelo mais humanitário de tratamento da saúde mental, que é, sobretudo, efetivado por meio da desinstitucionalização, passa a ser uma bandeira que caminha lado a lado do combate aos que sofrem com a dependência química. O RAPS também contribui para o processo pedagógico acerca desse front, já que se ocupa com estratégias educativas e de prevenção, como se depreende dos $\operatorname{artigos} 2^{\circ}$ e $4^{\circ}$ da Portaria n. 3.088/2011 ${ }^{16}$.

E não menos importante, a consolidação dessa rede torna mais claro o compromisso federativo (entre todos os entes federados) acerca da política de desinstitucionalização, já que o art. 14 traz as divisões de competência entre os entes ${ }^{17}$, incluindo o sistema de monitoramento e avaliação como responsabilidade compartilhada entre eles.

\subsection{Serviços Residenciais Terapêuticos (SRTs)}

Outro importante output diz respeito aos Serviços Residenciais Terapêuticos. Esse mecanismo é fruto de um diploma infralegal (Portaria n. 106/00 ${ }^{18}$, do Ministério da Saúde) que antecede o próprio marco regulatório principal, a Lei n. 10.216/01, também fruto dos debates que extrapolavam o âmbito legislativo.

Os SRT são complementares ao "De Volta Pra Casa", pela ausência de vínculos familiares dos loucos. Ou seja, são moradias destinadas a quem sofre o transtorno mental e deve ser reinserido em sociedade, porém, não é sabido de familiares que possam fazer o acolhimento ${ }^{19}$.

A implementação dos SRT condiciona a um Projeto Terapêutico. 0 art. $4^{\circ}$ da referida Portaria n. 106/00 expressamente traz como diretrizes que devem fazer parte do Projeto o seguinte: autonomia e reinserção social dos usuários, reabilitação psicossocial e percepção do usuário como cidadão e sujeito de direitos ${ }^{20}$.

Mencione-se, ainda sobre os Serviços Residenciais Terapêuticos, que por meio da Portaria n. 3.090, de 23 de dezembro de 2011, do Ministério da Saúde, repartiu as residências em duas modalidades (por isso os artigos $2^{\circ}-A$ e $2^{\circ}-B$ ). O Tipo I é destinado a quem sofre com transtorno, porém, em processo de desinstitucionalização (ou

15 BRASIL. Ministério da Saúde. Portaria n. 3.088, de 23 de dezembro de 2011. Disponível em <http:// bvsms.saude.gov.br/bvs/saudelegis/gm/2011/prt3088_23_12_2011_rep.html>. Acesso em 16 fev 2017.

16 Art. $2^{\circ}$ I, II, III, VI e XI. BRASIL. Idem. Art. $4^{\circ}$ I, II e III. BRASIL. Idem.

17 Art. 14. I, II e III. BRASIL. Idem.

18 BRASIL. Ministério da Saúde. Portaria n. 106, de 11 de fevereiro de 2000. Disponível em <http://www. saude.sc.gov.br/geral/planos/programas_e_projetos/saude_mental/portaria_106.htm>. Acesso em 20 abr 2017.

19 Art. $1^{\circ}$, Parágrafo único. BRASIL. Idem.

20 Art. $4^{\circ}$. BRASIL. Idem. 
seja, com menor grau de dependência). O Tipo II, por sua vez, a quem possui maior grau de dependência e cuidados permanentes.

\title{
2.5 Programa de Desinstitucionalização
}

Por mais que todos os outcomes mencionados até o momento compusessem a política pública de desinstitucionalização, essa estratégia só foi narrada como tal por meio da Portaria n. 2.840, de 29 de dezembro de 2014, do Ministério da Saúde.Foi criado o Programa de Desinstitucionalização como estratégia de desinstitucionalização do RAPS.

Pode-se dizer que o caminho que vinha sendo traçado deságua nesse programa, que só reforça o paradigma de abandono do modelo hospitalocêntrico, construído progressivamente de maneira institucional ao longo dos últimos quinze anos. $\mathrm{O}$ art. $2^{\circ}$ da referida Portaria aduz que:

\begin{abstract}
O componente Estratégias de Desinstitucionalização da RAPS é constituído por iniciativas que visam garantir às pessoas com sofrimento ou transtorno mental, e com necessidades decorrentes do uso de crack, álcool e outras drogas, em situação de internação de longa permanência, o cuidado integral por meio de estratégias substitutivas, na perspectiva da garantia de direitos com a promoção de autonomia e o exercício de cidadania, buscando-se sua progressiva inclusão social ${ }^{21}$.
\end{abstract}

Nesse sentido, o Programa de Desinstitucionalização ${ }^{22}$ segue em prol da política pública de desinstitucionalização, por exemplo, por meio da criação de uma Equipe de Desinstitucionalização ${ }^{23}$ e novamente a previsão e avaliação e monitoramento desse Programa ${ }^{24}$.

O marco regulatório a respeito da política pública de desinstitucionalização deixa claro que o abandono dos paradigmas de isolamento e repressão dos loucos não mais persiste, ao menos não deve mais persistir. Fica evidente a quantidade de mecanismos que prezam pela reinserção social de quem sofre transtornos mentais ("De Volta Pra Casa", Serviços Residenciais Terapêuticos, CAPS, RAPS e o próprio Programa de Desinstitucionalização).

Em que pese o "fim" dos hospitais psiquiátricos serem o objetivo imediato dessa política, os objetivos subjacentes, até mais relevantes do que esse, passam pela percepção de que quem sofre com transtorno mental é de fato sujeito portador de direitos fundamentais e que não pode carregar a pecha de estigmatizado. Portanto, será possível analisar a equação políticas públicas versus direitos fundamentais.

\section{Monitoramento da desinstitucionalização do município do Rio de Janeiro}

Apesar das diversas estratégias supracitadas em relação à desinstitucionalização, a realidade fática e normativa é sitiada por tensões ${ }^{25}$, as quais nem sempre são concordantes. Devido

21 BRASIL. Ministério da Saúde. Portaria n. 2.840, de 29 de dezembro de 2014. Disponível em <http:// bvsms.saude.gov.br/bvs/saudelegis/gm/2014/prt2840_29_12_2014.html>.Acesso em 21 abr 2017.

22 No trabalho, faremos a distinção entre Programa de Desinstitucionalização, para referir expressamente a Portaria 2.840/14, e política pública de desinstitucionalização, essa mais abrangente e a envolver todos os mecanismos de desinstitucionalização da saúde mental, inclusive o Programa de Desinstitucionalização.

23 Art. $5^{\circ}$ da Portaria n. 2.840/2014, do Ministério da Saúde. BRASIL. Idem.

24 Art. 20. Incisos I e II.. BRASIL. Idem. 
ao conflito, a análise de indicadores é o indício adequado para esta tensão, uma vez que seus dados apresentam componentes decisivos para entender as discrepâncias entre a normatividade e faticidade. Logo, pretende-se avaliar dados de monitoramento em contexto municipal, entendendo que o modelo de análise pode ser considerado como panorâmico, devido ao fato destes dados serem mais viáveis a um mapeamento da política pública.

Mesmo que o marco regulatório apresente uma incidência de programas de desinstitucionalização a partir dos anos 2000, algumas práticas já eram exercidas por outros institutos mentais do município do Rio de Janeiro, como por exemplo, o Instituto Philippe Pinel, que oferecia residência terapêutica ${ }^{26}$, sendo acompanhado posteriormente por outras experiências como residências terapêuticas de Nise da Silveira e Juliano Moreira.

\subsection{Serviços Residenciais Terapêuticos (SRTs)}

Em uma análise, os Serviços Residenciais Terapêuticos (SRTs) no município carioca contavam com 17 residências terapêuticas em $2004^{27}$, que absorviam um atendimento de cerca de 70 moradores, avançando para 33 residências em $2010^{28}$, número que se denota incipiência em concretização deste programa, visto que demonstra uma avanço de apenas 16 novas residências em um período de 6 anos.

Os SRTs são considerados um dos principais artifícios em combate ao modelo hospitalocêntrico, mesmo assim, os Relatórios Anuais de Gestão de 2011, 2012, 2014 e 2015 não expõem novas criações. Contrário a criação, o Relatório de $2013^{29}$ atesta uma especulação prévia sobre os SRTs: sua estagnação, já que não apresentam novas criações, mesmo com suas diretrizes de expansão.

Os avanços desse mecanismo apresentam números tímidos, de acordo com a Secretaria Municipal de Saúde, até dezembro de 2013, existiam 51 SRTs e 23 Moradias Assistidas, apoiando um total de 315 pacientes. O Plano Municipal de Saúde e sua previsão entre os anos de 2014 e 2017eram de uma meta de 352 pacientes $^{30}$, ou seja, um progresso considerado pequeno para a importância do programa.

\subsection{Centro de Assistência Psicossocial (CAPS)}

O Centro de Assistência Psicossocial, outro serviço essencial para a desinstitucionalização, tem dados que revelam indicadores averiguáveis, podendo explorar a real situação da efetivação deste programa. As informações utilizadas para a seguinte análise se baseiam em três pontos-chaves: o número de atendidos, a quantidade de núcleos (CAPS) e a taxa de cobertura (a cada 100.000 habitantes).

términos de teoria del discurso. Trad. Manuel Jiménez Redondo. 6. ed. Madrid: Editorial Trotta. 2010. NEVES, Marcelo.Entre Têmis e Leviatã: uma relação difícil: o Estado Democrático de Direito a partir e além de Luhmann e Habermas. 3. ed. São Paulo: Martins Fontes, 2012. p. 115.

26 RIO DE JANEIRO. Secretaria Municipal de Saúde. Lar Abrigado por Instituo Philippe Pinel. Disponível em <http://www.sms.rio.rj.gov.br/pinel/media/pinel_lar_abrigado>. Acesso em: 05 mai 2017.

27 BRASIL. Ministério da Saúde. Secretaria de Atenção à Saúde. Departamento de Ações Programáticas Estratégicas. Residências terapêuticas: o que são, para que servem. Brasília: Ministério da Saúde, 2004, p.15.

28 RIO DE JANEIRO. Prefeitura da Cidade do Rio de Janeiro. Secretaria Municipal de Saúde. Relatório Anual de Gestão: 2010. p. 60

29 RIO DE JANEIRO. Prefeitura da Cidade do Rio de Janeiro. Secretaria Municipal de Saúde. Relatório Anual de Gestão: 2013. Disponível em <http://www.rio.rj.gov.br/dlstatic/ 10112/3700816/4138514/RAG2013 aprovado> . Acesso em 05 mai 2017.

30 RIO DE JANEIRO. Secretaria Municipal de Saúde. Plano Municipal de Saúde: 2014-2017. Disponível em<http://www.rio.rj.gov.br/dlstatic/10112/3700816/4128745 PMS_20142017>. Acesso em 05 mai 2017. 
Segundo o Relatório Anual de Gestão de 2010, o município contava com 19 CAPS, sendo 5.000 pacientes atendidos naquele ano, não contando com a informação de taxa de cobertura. Atualmente, existem 30 CAPS, sendo apenas 26 de responsabilidade do município ${ }^{31}$, meta que deveria ser atingida em 2014, de acordo com o Plano Municipal de Saúde de 2014-2017, sendo 38 unidades até o final de 2017, o que não está sendo realizado no momento.

Outra análise feita foi sobre Plano Municipal de Saúde, foi sua meta de atender pouco mais de 6.000 pacientes até 2017, número pequeno se comparamos aos 5.000 supramencionados em 2010, assim como sua abrangência que, de acordo com o Relatório de 2015, sua cobertura foi de 0,52 , enquanto a meta prevista pelo Plano Municipal de Saúde de 2014-2017 ${ }^{32}$ era de 0,63 (reitera-se que a cobertura de abrangência é calcula a cada 100.000 habitantes).

Logo, mesmo com seu aumento em atendidos, cobertura e quantidade de núcleos, seus números expressam um aumento lento, que ainda não poderia ser considerado satisfatório, visto que o CAPS representa uma ferramenta importante para concretizar a política antimanicomial.

\subsection{Leitos Hospitalares}

O grande precursor na nova política de saúde mental foi o fechamento de leitos hospitalares, sendo um dos indicadores mais conclusivos para observação da alteração do modelo anterior, no qual predominada o encarceramento do doente mental e o desvinculada de laços sociais, inibindo seus direitos fundamentais.

No município do Rio de Janeiro, foram contabilizados 5.000 leitos entre 1995-2000, sendo verificados 3.000 leitos em 2005, interando de que essa contabilização é apenas aos leitos vinculados ao Sistema Único de Saúde. Este número foi se reduzindo ao longo, observando um número de 2.745 leitos em $2008^{33}$, sendo seguido por um vácuo de informação entre os anos de 2009 e 2013, nos quais os Relatórios Anuais de Gestão não apresentavam nenhum dado a respeito do fechamento de leitos.

Os dados mais recentes apresentados revelam uma intenção de "ampliar as ações de desinstitucionalização com vistas à redução do número de leitos de longa permanência e consequente ampliação da rede de atenção psicossocial"34. O Plano Plurianual 20142017 tem a expectativa de fechar 60 leitos em 2016 e mais 60 em $2017^{35}$. Interpretar dados como estes, apesar de não revelar a realidade fática, mostram um empenho na mudança de paradigma do modelo hospitalocêntrico.

\section{Considerações finais}

31 Informações foram extraídas na própria página do CAPS no website da Prefeitura Municipal do Rio de Janeiro. Disponível em <www.rio.gov.br $>$.

32 RIO DE JANEIRO. Secretaria Municipal de Saúde. Plano Municipal de Saúde: 2014-2017. Disponível em <http://www.rio.rj.gov.br/dlstatic/10112/3700816/4128745/PMS_20142017>. Acesso em 05 mai 2017.

33 RIO DE JANEIRO. Secretaria Municipal de Saúde e Defesa Civil. Plano Municipal de Saúde do Rio de Janeiro: 2010 a 2013. Disponível em <http://www.rio.rj.gov.br/dlstatic/10112/3700816/4130215/ PLANOMUNICIPALDESAUDE20102013>. Acesso em 13 mai 2017.

34 RIO DE JANEIRO. Prefeitura da Cidade do Rio de Janeiro. Decreto n. 41.289 de 26 de fev de 2016. Atualização do Plano Plurianual 2014-2017, para o período de 2016-2017. Diário Oficial do Município do Rio de Janeiro, Ano XXIX, nº 231, publicado em 29 de fev de 2016, p. 162.

35 RIO DE JANEIRO. Secretaria Municipal de Saúde. Plano Municipal de Saúde do Rio de Janeiro: 20142017.Disponível em <http://www.rio.rj.gov.br/dlstatic/10112/3700816/4128745/PMS_20142017>. Acesso em 05 mai 2017. 
Ainda que a política pública de desinstitucionalização da saúde mental esteja em expansão conforme aludido acima, há uma carência de sua verificação em números, sendo sua averiguação fruto de uma análise dedutiva, o que deve ser alterado futuramente com a Lei de Acesso a Informação (LEI $\mathrm{n}^{0} 12.527 / 11$ ), possibilitando uma maior transparência dos dados. Contudo, o marco regulatório oferece base para orientação de que a dita política está se concretizando.

O monitoramento de indicadores é a maneira mais satisfatória de indagar sobre o alinhamento de uma política pública e sua atuação, fato que foi insuficiente, devido ao déficit de dados e ausência de sistematicidade, comprometendo a obtenção da informação e, em consequência, a apuração da concretização da política publica.

Pode-se verificar a partir do estudo que a desinstitucionalização está se fortificando como padrão de tratamento em saúde mental, podendo ser analisada a partir de programas que visam o fechamento de leitos, a reinserção social do paciente e o abandono do modelo hospitalocêntrico, vide programas mencionados no capítulo 2. Todavia, quanto aos dados encontrados, verificamos uma cultura de pouca sistematização de indicadores, comprometendo a mensuração da real situação.

Alguns fatores externos não cooperam com as dificuldades do campo de atuação da saúde mental, como a especulação imobiliária e a valorização de áreas que prejudicam a implantação de mais residências terapêuticas e a gravidade do transtorno mental, fato que impossibilita algumas políticas de desinstitucionalização.

Embora não tenhamos um diagnóstico preciso, a política de desinstitucionalização está caminhando para uma maior garantia de direitos fundamentais dos pacientes, uma vez que estão sendo tomadas medidas que diminuíam seu encarceramento e invisibilidade vistos na redução de leitos mencionados no capítulo 3 e no aumento de seu atendimento e cobertura, ao menos com relação ao município do Rio de Janeiro.

Os direitos fundamentais dos indivíduos acometidos por transtornos mentais não devem ser lidos apenas como o confronto a privação ou restrição de sua liberdade, mas a outras relações como saúde, segurança e direitos sociais. Verificamos uma política de desinstitucionalização que não objetiva apenas combater o modelo hospitalocêntrico tão debatido durante este trabalho, mas a criação de outras formas de tratamento que visam conferir proteção aos direitos fundamentais dos pacientes, fato que simboliza um avanço à questão mental e a discussão sobre direitos fundamentais. 


\section{Referências bibliográficas}

ARENDT, Hannah. Origens do totalitarismo. São Paulo: Companhia das Letras, 1989. ASSEMBLEIA LEGISLATIVA DO ESTADO DO RIO GRANDE DO NORTE. Lei n. 6.758 de 04 de janeiro de 1995. Disponível em <http://www.al.rn.gov.br/portal/_ups/legislacao//6.758. pdf $>$. Acesso em 20 abr 2017.

ASSEMBLEIA LEGISLATIVA DO ESTADO DO RIO GRANDE DO SUL. Lei n. 9716 de 07 de agosto de 1992. Disponível em <http://www.al.rs.gov.br/legis/M010/M0100099.ASP? Hid_Tipo=TEXTO\&Hid_Todas Normas $=15281 \&$ hTexto $=\& H i d \_I D N o r m a=15281>$. Acesso em 20 abr 2017.

BARCELLOS, Ana Paula de. Acesso à informação: os princípios da Lei $n^{0}$ 12.527/11. Questio Juris. v. 08, n. 03, Rio de Janeiro, 2015. pp. 1741-1759.

BERTOLLI FILHO, Claudio. História social da tuberculose e do tuberculoso: 19001950. Rio de Janeiro: Editora Fiocruz, 2001. Disponível em <http://static.scielo.org/ scielobooks/4/p df/bertolli-9788575412886.pdf〉 Acesso em 20abr 2017.

BRASIL. Constituição da República Federativa do Brasil. 1988. Disponível em <http:// www.planalto.gov.br/ccivil_03/constituicao/ConstituicaoCompilado.htm〉. Acesso em 20 abr 2017.

BRASIL. Diário do Congresso Nacional, de 29 de setembro de 1989, seção I, pp. 10.69610.697.

BRASIL. Lei n. 10.216, de 6 de abril de 2001. Disponível em <http://www.planalto.gov. br/ccivil_03/Leis/LEIS_2001/L10216.htm〉. Acesso em 20 abr 2017.

BRASIL. Lei n. 10.708, de 31 de julho de 2003. Disponível em <http://www.planalto.gov. br/ccivil_03/Leis/2003/ L10.708.htm>. Acesso em 20 abr 2017.

Brasil. Ministério da Saúde. Secretaria-Executiva. Secretaria de Atenção à Saúde. Legislação em saúde mental: 1990-2004. 5a ed. ampl. Brasília: Ministério da Saúde, 2004.

BRASIL. Ministério da Saúde. Portaria n. 106, de 11 de fevereiro de 2000. Disponível em <http://www.saude.sc.gov.br/geral/planos/programas_e_projetos/saude_mental/ portaria_106.htm>. Acesso em 20 abr 2017.

BRASIL. Ministério da Saúde. Portaria n. 130, 26 de janeiro de 2012. Disponível em < http://bvsms.saude.gov.br/bvs/saudelegis/gm/2012/prt0130_26_01_2012.html>. Acesso em 16 fev 2017.

BRASIL. Ministério da Saúde. Portaria n. 336, de 19 de fevereiro de 2002. Disponível em 〈http://www.maringa.pr.gov.br/cisam/portaria336.pdf〉. Acesso em16 fev 2017

BRASIL. Ministério da Saúde. Portaria n. 2.840, de 29 de dezembro de 2014. Disponível em<http://bvsms.saude.gov.br/bvs/saudelegis/gm/2014/prt2840_29_12_2014.html〉. Acesso em 21 abr 2017.

BRASIL. Ministério da Saúde. Portaria n. 3.088, de 23 de dezembro de 2011. Disponível em <http://bvsms.saude.gov.br /bvs/saudelegis/gm/2011/prt3088_23_12_2011_rep. html>. Acesso em 16 fev 2017 
BRASIL. Ministério da Saúde. Portaria n. 3.089, de 23 de dezembro de 2011. Disponível em<http://bvsms.saude.gov.br/bvs/saudelegis/gm/2011/prt3089_23_12_2011_rep. html>.Acesso em 16 fev 2017.

BRASIL. Ministério da Saúde. Reforma Psiquiátrica e política de saúde mental. Conferência Regional de Reforma dos Serviços de Saúde Mental: 15 anos depois de Caracas. Nov 2015. Disponível em: 〈http://bvsms.saude.gov.br/bvs/publicacoes / Relatorio15_anos_Caracas.pdf $>$. Acesso em 16 fev 2017.

BRASIL. Ministério da Saúde. Secretaria de Atenção à Saúde. Departamento de Ações Programáticas Estratégicas. Saúde Mental no SUS: os centros de atenção psicossocial Brasília: Ministério da Saúde, 2004. p. 13.

BRASIL. Ministério da Saúde. Saúde Mental em Dados - 12, ano 10, nº 12. Informativo eletrônico. Brasília: outubro 2015.

BRASIL. Ministério da Saúde. Secretaria de Atenção à Saúde. Departamento de Ações Programáticas Estratégicas. Residências terapêuticas: o que são, para que servem. Brasília: Ministério da Saúde, 2004.

CASTRO, Selma Munhoz Sanches de; WATANABE, Helena AkemiWada. Isolamento compulsório de portadores de hanseníase: memória de idosos. História, Ciências, Saúde-Manguinhos (Online). vol. 16, n. 2, 2009, pp. 449-487. Disponível em: <http:// dx.doi.org/ 10.1590/S0104-59702009000200010>. Acessoem 16 fev 2017.

GREEN, Maria. What we talk about when we talk about indicators: currente approaches to human rights measurement. Human Rights Quaterly. v. 23.4, 2001. Disponívelem<https://muse.jhu.edu/article/13805〉.Acesso em 12 mar 2017. p. 1076.

GUEDES, Ariane da Cruz; KANTORSKI, Luciane Prado; PEREIRA, Patrícia Mirapalheta; CLASEN, Bianca Neme; LANGE, Celmira; MUNIZ, RosaniManfrin. A mudança nas práticas em saúde mental e a desinstitucionalização: uma revisão integrativa. Revista Eletrônica de Enfermagem (Internet). v. 10, n. 3, 2010. Disponível em <http://dx.doi. org/10.5216/ree.v12i3.8198>. Acesso em 12 mar 2017.

HABERMAS, Jürgen. Facticidad y Validez: sobre elderecho y e Estado democrático de derecho em términos de teoria del discurso. Trad. Manuel Jiménez Redondo. 6. ed. Madrid: Editorial Trotta. 2010.

JONES, Harry. A guide to monitoring and evaluating policy influence. London: Overseas Development Institute, 2011. Disponívelem<http://www.odi.org/sites/odi. org.uk/files/odi-assets/publications-opinion-files/6453.pdf>.Acesso em 12 mar 2017.

MACKINNON, Catherine. Desejo e Poder. In. MIGUEL, L. F. e BIROLLI, F. (org) Teoria política feminista: textos centrais. Rio de Janeiro: Editora Horizonte, 2013, pp. 231250

MESQUITA, José Ferreira; NOVELLINO, Maria Sallet Ferreira; CAVALCANTI, Maria Tavares. A reforma psiquiátrica no Brasil: um novo olhar sobre o paradigma da saúde mental. In: XVII Encontro Nacional de Estudos Populacionais, ABEP. Caxambu, 2010.

NEVES, Marcelo. Entre Têmis e Leviatã: uma relação difícil: o Estado Democrático de Direito a partir e além de Luhmann e Habermas. 3. ed. São Paulo: Martins Fontes, 2012

NORTON, Andy; ELSON, Diane. What's behind the budget? Politics, rights and accountability in the budget process. London: Overseas Development Institute, 2002. Disponívelem: <http://www.unicef.org/socialpolicy/files/What_is_behind_the_ budget_NortonElson02.pdf >. Acessoem 19 abr 2017. 
NUSSBAUM, Martha C. Objectification. Philosophy and Public Affairs. v. 24, n. 4. 1995. pp. 249-291.

ORGANIZAÇÃO Mundial da Saúde (OMS). Declaração de Caracas. 14 nov 1990. Disponível em <http://pfdc.pgr.mpf.mp.br/atuacao-e-conteudos-de-apoio/legislacao/ saude-mental/declaracao_caracas . Acesso em 20 abr 2017.

RIO DE JANEIRO. As residências terapêuticas no município do Rio de Janeiro: habitando a casa, a cidade e a vida. Rio de Janeiro: Secretaria Municipal de Saúde, 2014.

RIO DE JANEIRO. Secretaria Municipal de Saúde. Lar Abrigado por Instituo Philippe Pinel. Disponível em <http://www.sms.rio.rj.gov.br/pinel/media/pinel_lar_abrigado. htm>. Acesso 05 mai 2017.

RIO DE JANEIRO. Lei n. 7.211. Plano Plurianual - PPA 2016-2019, de fevereiro de 2016. V. 2.

RIO DE JANEIRO. Secretaria Municipal de Saúde e Defesa Civil. Plano Municipal de Saúde do Rio de Janeiro: 2010 a 2013. Disponível em <http://www.rio.rj.gov.br/ dlstatic/10112/3700816/4130215/ PLANOMUNICIPALDESAUDE20102013.pdf〉. Acesso em 13 mai 2017.

RIO DE JANEIRO. Secretaria Municipal de Saúde. Plano Municipal de Saúde: 20142017. Disponível em <http://Www.rio.rj.gov.br/dlstatic/10112/3700816/4128745/ PMS_20142017.pdf >. Acesso em 05 mai 2017.p. 102.

RIO DE JANEIRO. Prefeitura da Cidade do Rio de Janeiro. Política de Saúde Mental na Cidade do Rio de Janeiro. Subsecretaria de Ações e Serviços de Saúde. Coordenação de Saúde Mental.

RIO DE JANEIRO. Prefeitura da Cidade do Rio de Janeiro. Secretaria Municipal de Saúde. Relatório Anual de Gestão 2009. Disponível em <http://www.rio.rj.gov.br/ dlstatic/10112/3700816/4114103/RAG2009_versaofinal.pdf >. Acesso em 05 mai 2017.

RIO DE JANEIRO. Prefeitura da Cidade do Rio de Janeiro. Secretaria Municipal de Saúde. Relatório Anual de Gestão: 2010. Disponível em <http://www.rio.rj.gov.br/ dlstatic/10112/3700816/4114104/RAG2010.pdf >. Acesso em 05 mai 2017.

RIO DE JANEIRO. Prefeitura da Cidade do Rio de Janeiro. Secretaria Municipal de Saúde. Relatório Anual de Gestão: 2011. Disponível em <http://www.rio.rj.gov.br/ dlstatic/10112/3700816/4114105/RAG2011.pdf . Acesso em 05 mai 2017.

RIO DE JANEIRO. Prefeitura da Cidade do Rio de Janeiro. Secretaria Municipal de Saúde. Relatório Anual de Gestão: 2012. Disponível em <http://www.rio.rj.gov.br/ dlstatic/10112/3700816/4114105/RAG2012.pdf >. Acesso em 05 mai 2017.

RIO DE JANEIRO. Prefeitura da Cidade do Rio de Janeiro. Secretaria Municipal de Saúde. Relatório Anual de Gestão: 2013. Disponível em 〈http://www.rio.rj.gov.br/ dlstatic/10112/3700816/4138514/RAG2013 aprovado.pdf>. Acesso em 05 mai2017.

RIO DE JANEIRO. Conselho Municipal de Saúde. Relatório Anual de Gestão:2014. Disponível em <http://Www.rio.rj.gov.br/dlstatic/10112/3700816/4138513/ RAG2014aprovado.pdf $>$. Acesso em 10 mar 2017.

RIO DE JANEIRO. Prefeitura da Cidade do Rio de Janeiro. Secretaria Municipal de Saúde. Relatório Anual de Gestão:2015. Disponível em <http://www.rio.rj.gov.br/ dlstatic/10112/3700816/4114104/RAG2015.pdf〉. Acesso em 17fev 2017.

ROSA, Abílio da Costa; LUZIO, Cristina Amélia; YASUI, Sílvio. As Conferências Nacionais de Saúde Mental e as premissas do modo psicossocial. Saúde em Debate, v. 25, n. 58, 
mai/ago 2001. pp. 12-25.

ROSENFELD, Michel. A identidade do sujeito constitucional. Belo Horizonte: Mandamentos, 2003.

SOUZA, Jessé. A visibilidade da raça e a invisibilidade da classe: contra as evidências do conhecimento imediato. In: brasileira. Belo Horizonte; UFMG, 2006. pp. 71-95.

SOUZA, Vinícius Rauber e. Contrarreforma psiquiátrica: o modelo hospitalocêntrico nas políticas públicas em saúde mental no Rio Grande do Sul. Dissertação (Mestrado em Ciências Sociais) - Faculdade de Filosofia e Ciências Humanas, Programa de PósGraduação em Ciências Sociais, Pontifícia Universidade Católica do Rio Grande do Sul (PUC/RS), Porto Alegre, 2010.

VENTURINI, Ernesto. A desinstitucionalização; limites e possibilidades. Revista Brasileira de Crescimento e Desenvolvimento Humano. v. 20, n. 1, São Paulo, abr 2010. Disponível em: <http://pepsic.bvsalud.org/scielo.php? script=sci_arttext\&pid=S010412822010000100018\&Ing=pt\&nrm=iso>. Acesso em 20abr 2017

VIOLA, Ana Clara. Longo Caminho a percorrer na volta para a sociedade. O Ministério Público e a desinstitucionalização em saúde mental. Dissertação (Mestrado Profissional em Saúde Pública) - Escola Nacional de Saúde Pública Sérgio Arouca, Fiocruz, Rio de Janeiro, 2015. 